BOOK REVIEW

\section{"Musical Excellence: Strategies and techniques to enhance performance"}

\author{
Dianna T. Kenny \\ Australian Centre for Applied Research \\ in Music Performance \\ Sydney Conservatorium of Music, \\ University of Sydney
}

Oxford University Press 2004

Edited: Aaron Williamon

I showed this book to my 17-year-old daughter, an aspiring cellist, and suggested that she read those parts of the book that caught her attention. I told her that I would welcome her comments and feedback. Some time later, she returned with the book and said, "This book looks really interesting but I wonder if Fournier, du Pre or Isserlis would read it or need it." She was surprised when I told her that while these three cellists may match her conception of artists so in control of their art, their technique and their nerves as to obviate the need for such a book, others of equal musical standing, such as Pablo Casals, who suffered performance anxiety, may well have benefited from knowledge that is accumulating from disciplines that collectively comprise the science of music. It is a common misperception that outstanding musicians do not experience doubts, anxieties and crises of confidence or engage in inefficient or otherwise unhelpful performance preparation routines that could benefit from systematic analysis, enhancement or remediation. Academics and researchers in music performance face their own set of core dilemmas, which are so eruditely captured in the eloquent foreword to the book by Janet Ritterman. Who is this book's audience, and what are its goals? We do not need to wait long to find out. Aaron Williamon answers our questions in the opening paragraph of his chapter, A guide to enhancing musical performance. He states "One of the most exciting challenges facing music researchers is to develop ways of assisting performers to meet those demands" of music performance that require musicians to "process and execute complex musical information with novel artistic insight, technical facil- ity and a keen awareness of audiences' expectations... efficiently and effectively" (p. 3).

Most music researchers note that in other domains of performance, such as sport, test-taking and public speaking, there are already strong bodies of research to guide pedagogy, training and practice. Appleman (1967) recognized the problem in music performance when he asserted "vocal pedagogy cannot survive as an independent educational entity if the physiological and physical facts, which comprise its core, remain subjects of sciolism (superficial knowledge). Researchers must constantly interpret these scientific facts so that they might become realistic pedagogical tools that may be employed by future teachers of voice" (p. 5). This theme was taken up by Vennard (1968): "There are certain fundamentals of the science of acoustics that all voice teachers should know" (p. 1). Since the 1980 s technology to measure vocal acoustics has become steadily more sophisticated and has been increasingly used in experimental research, with the findings of such research now being incorporated into texts on singing (Callaghan, 2000; Miller, 1996, 1998; Sundberg, 1988). International authority Richard Miller (1998) summed up: "It is the responsibility of the singing teacher in a scientific age to interpret and expand vocal traditions through the means of current analysis so that the viable aspects of tradition can be communicated in a systematic way" (p. 299).

These comments on vocal pedagogy apply equally to the preparation of instrumental musicians. Although application of science to practice has been slow in the performing arts, Musical Excellence convinces us that progress continues to be made and that much of it is captured in the very tightly written chapters that comprise this book. Peter Webster (2002), in his review of Parncutt's and McPherson's edited book (2002), The science and psychology of music performance: Creative strategies for teaching and learning, states "One sign of a maturing profession is the continuing emergence of volumes devoted to the review and interpretation of research findings" (p.1). These books are the measure of maturity and our profession, while young, can be proud of the emerging traditions of rigor and excellence evident in these works.

The book is divided into three sections: The oddly titled Part 1: Prospects and limits; part 11: Practice strategies and Part III: Techniques and interventions.

Corresponding author: Dianna Kenny, Australian Centre for Applied Research in Music Performance, Sydney Conservatorium of Music C41,University of Sydney, Australia 2000. Email: D.Kenny@fhs.usyd.edu.au 
The opening chapter by Williamon provides the road map for the book with a neat summary of each of the chapter's contents. There is a short section on music performance anxiety titled "Managing and overcoming obstacles" and no treatment would be complete without the Yerkes-Dodson inverted U-curve. However, even this curve has become more complex as our understanding of music performance anxiety develops. We know, for example, that simpler tasks can be performed at higher levels with greater arousal than more complex tasks and that well learned tasks can be performed best with a higher level of arousal than less well learned tasks. Further, a person who is high trait anxious will reach an optimum level of arousal before a low trait anxious individual and care must therefore be taken in the application of motivational strategies or personal enhancement programs with individual performers. We are provided with a table on p.10 that outlines 29 areas in which musical performance may be enhanced in the physical, psychological, and musical skills domains. Each chapter follows the same format and concludes with suggestions for additional reading.

In Chapter 2, Chaffin and Lemieux ask the burning question, "Are exceptional musicians born or made?" (p.19). What role does innate talent and temperament play in the achievement of musical excellence? These questions quickly give way to the sobering evidence of the role of training and practice in all fields of human endeavour, and we are reminded of the 10 year rule and the 10000 hours of practice needed to reach the dizzy heights of the concert stage. Component skills such as concentration, goal setting, use of flexible practice strategies and self-evaluation are discussed and argued to be underpinned by motivation. While all of these elements are acknowledged essentials in the achievement of excellence, so too must we acknowledge the role of individual differences in giftedness. The failure to date to find definite characteristic clusters of the gifted among academic achievement and leisure activities, cognitive and motivational personality factors, and school and family socialization conditions (Heller, 1991) leads us to the conclusion that there are elements to giftedness that currently remain mysterious and therefore beyond influence.

In Chapter 3, Parry presents some basic common sense, often ignored by aspiring or successful musicians, to recognize the physical demands of playing an instrument. He outlines specific areas of possible physical difficulty that may be experienced in the playing of several instruments and concludes with some general advice as to how to prevent injury, with cross references to chapters 9,10 , and 12 .
McPherson and Schubert struggle with the vexed issue of measurement in Chapter 4, Measuring performance enhancement in music, the last chapter of Part 1 of the book. They begin the chapter with an incorrect definition of a norm referenced test, which they describe as "ranking a performance in comparison with others... norm ranking procedures are common in competitions, eisteddfods, ... where the intention is to rank the musicians from most to least accomplished" (p. 60). A norm-referenced test compares a person's score against the scores of a group of people who represent the population from which the test taker comes, and for whom a set of standard scores have been calculated. Results from norm referenced tests are usually expressed as a percentile, an age or grade equivalent (standard) score, or a stanine. This is a very different process to that which happens in competitions and eisteddfods, which are rankings of performers whose only similarity is that they have entered the same competition and meet inclusion criteria (eg upper age limit, performance program etc). Many studies have shown that interjudge reliability is low (Oates, Bain, Davis, Chapman \& Kenny, in press) so there is much to be done in the area of assessment. There is good coverage of factors contributing to measurement error, including extra musical and non musical factors.

Chapter 5 opens Part 2, Practice strategies with a most welcome coverage of Strategies for individual practice by Harald Jorgensen. This chapter is just plain good sense, easy to read and understand and recommended reading for all music students. This is followed by a similar chapter from Jane Davidson and Elaine King on Strategies for ensemble practice (Chapter 6) that once again is thoughtful, clear and thorough, with captivating case studies that illuminate the multi-layered forms of communication that occur between ensemble members, as well as the increasing synchrony that is observed musically and behaviorally in successful ensembles.

In Chapter 7 Strategies of memorizing music, Ginsborg neatly summarizes some of the key elements required for this daunting task, underpinning the importance of intention to remember, use of all the sensory domains and the role of musical analysis as essential features of memorization. Like most cognitive and meta-cognitive skills, there are vast individual differences in the capacity for memorization. One of my colleagues at the Sydney Conservatorium of Music and one of Australia's finest pianists, Gerard Willems, recounted an interesting anecdote about the relationship between the ability to memorize music and the 
skill of sight-reading. He told me that he attended a concert by Claudio Arrau in Sydney in 1965. Arrau was requested to play the Australian national anthem (which was, at that time, God Save the Queen) and that the concert organizers had only provided him with the music on the night. Willems said that Arrau made three errors during his sight-reading of this relatively short and simply harmonized melody, after which he sat at the keyboard and played from memory several Beethoven piano sonatas flawlessly and with wonderful musicianship. Willems then told me that in his experience, pianists excel either at memorization or sight-reading, but rarely in both. He said those who could memorize aspired to the concert stage as soloists and those who could sight-read became accompanists and repetiteurs. It is conversations such as these that stimulate and direct the music researcher to investigate questions of importance and relevance to performers.

Strategies for sight-reading and improvising music (Chapter 8 ) by Sam Thompson and Andreas Lehmann is an intriguing chapter. I have rarely seen these two skills treated together and indeed the authors anticipate the reader's surprise at this confluence, particularly in view of the chapters on improvisation and sight reading in Parncutt and McPherson in which each receives its own treatment: improvisation is described as a creative performance art while sight reading is described as a "reconstructive process" (p. 144). However, Thompson and Lehmann proceed to mount a cogent argument for their conceptual similarity: "both sight-reading and improvisation require the online creation and execution of motor program sequences in response to a stimulus" (p. 151) and differ primarily in the nature of the referent (external for sight-reading, internal for improvisation). The final words of advice are that both are greatly enhanced from a strong musical knowledge base.

Part 3 opens with Chapter 9 on Physical fitness by Adrian Taylor and David Wasley and an argument is presented for the inclusion of moderate intensity exercise as part of one's lifestyle and in pre performance routines as a form of anxiety management (although there is not yet strong evidence of its efficacy for this purpose). However, there is ample evidence to indicate that exercise is effective in enhancing physical and mental well being and should be encouraged universally.

In chapter 10, Alexander Technique, Valentine presents a balanced overview of the current knowledge base on Alexander Technique (AT) and wisely cautions readers about the limitations in both theory and research with respect to its application to music performance. While evidence is emerging that AT may be effective in some domains, for example, decreasing self-perceived disability in Parkinson's Disease (Stallibrass, Sissons, \& Chalmers, 2002), care should be taken not to over-generalize claims of effectiveness in other domains until supportive evidence is available. For example, there is only one empirical study on the effects of AT on music performance (Valentine, Fitzgerald, Gorton, Hudson, \& Symonds, 1995) that provides very weak evidence of efficacy (Kenny, 2005).

In Chapter 11, Physiological self-regulation: Biofeedback and neurofeedback, Gruzelier and Egner essentially summarize their own body of work in the area of neurofeedback, a "technique that teaches the individual how to control the rhythmic electrical activity of the brain" (p. 198). Early studies of efficacy in the area of reducing muscle tension in music performance relied on case studies, small groups and self-report outcomes. Recently, a number of methodologically stronger studies have demonstrated benefits of neurofeedback training in a number of areas, including with children with ADHD (Fuchs, Birbaumer, Lutzenberge, Gruzelier \& Kaiser, 2003). While this is an intriguing area of research, there is currently too great a disjunction between science and what is possible in the music studio. It is also questionable as to what discernible differences in musical performance quality are represented by an average improvement in rating in the neurofeedback training condition of .6 on a 10 point rating scale. This effectively represents a $6 \%$ improvement, but what this means in terms of musical improvement remains to be assessed. Egner, Strawson and Gruzelier (2002) themselves acknowledge that while neurofeedback can effectively alter theta/alpha wave ratios, clinical (or in this case, artistic) relevance needs to be addressed.

Mental skills training, Chapter 12 by Christopher Connolly and Aaron Williamon, is another 'how to' chapter of relevance to students. The central issue in mental skills training, which could perhaps have been more explicitly articulated, is that performers are highly individualized with respect to what skills work best under different performance conditions. The type and amount of preparation needed is determined by a range of factors, such as temperament, trait anxiety, task complexity, task mastery, and familiarity with program and performance venue, among others. Further, mental rehearsal and mental imagery are skills most often practiced by advanced performers already fami- 
liar with the appropriate detailed physical sensations of their task (Suinn, 1997). They are part of the total regime of musical preparation that must, like physical practice, be acquired over a long period of deliberate practice.

In Chapter 13 Feedback learning of musical expressivity, Patrik Juslin, Anders Friberg, Erwin Schoonderwaldt and Jessika Karlsson, have offered an excellent synthesis of an elusive and difficult concept in music, that of musical expressivity. Although very few would disagree that music is an expressive art form, the actual nature of musical expression has eluded definition, and as a result the explicit teaching of musical expression has not formed an integral part of musical education. They begin by challenging common myths about expressivity, summarize factors that may influence expressivity in music performance and present Juslin's GERMS model. This is followed by a neat summary of available research to date. They then outline their novel approach incorporating feedback learning of musical expressivity. The computer software has a strong pedagogical focus and does not neglect the ease of application by the learner, a feature often missed in the development and application of technology to music learning and teaching. To date, most research on performance and emotion has focused on how performers can use specific musical 'cues' to communicate an intended emotion to their audience in order to increase the accuracy of listeners' perception of the performers' intended emotion. Research in the area now needs to progress into examining emotional engagement in audiences, rather than just their ability to correctly identify the communicated emotion.

The book concludes with Chapter 14, Drugs and musical performance by Robert West. West rightly points out that there are very few studies on the effects of drugs on musical performance. Nubé (1991) published a review of the impact of beta-blockers on music performance anxiety and a brief overview of other drugs, such as anxiolytics and antidepressants has been provided by Sataloff, Rosen, and Levy (2000). There are unlikely to be further studies because of the more rigorous ethical requirements for research in recent years. West provides succinct and readable accounts of the nature and effects of the most commonly used substances including alcohol, caffeine, nicotine, antidepressants, beta-blockers, tranquilizers and the illicit drugs (amphetamines, cannabis, cocaine, ecstasy, hallucinogens and opiates). He concludes with sensible guidelines for use.

Williamon has garnered the collective expertise of an impressive array of music scholars to produce a book of quality. Different chapters in the book will be variously useful for academics, teachers and both music research and performance students. It will be a worthwhile addition to all Conservatoria libraries.

\section{References}

Appelman, D.R. (1967). The Science of vocal pedagogy. Bloomington, Ind.: Indiana University Press.

Callaghan, J. (2000) Singing and voice science. San Diego,California: Singular Publishing Group.

Egner, T., Strawson, E. \& Gruzelier, J.H. (2002). EEG signature and phenomenology of alpha/theta neurofeedback training versus mock feedback. Applied psychophysiology and biofeedback, 27, 4, 261-70. |WwW

Fuchs, T., Birbaumer, N., Lutzenberge, W., Gruzelier, J.H., \& Kaiser J. (2003). Neurofeedback treatment for attention-deficit/hyperactivity disorder in children: a comparison with methylphenidate. Applied Psychophysiology and Biofeedback, 28, 1, 1-12, 2003. WWW

Heller, K. A (1991). The nature and development of giftedness: A longitudinal study. European Journal for High Ability, 2, 2, 174-188.

Kenny, D.T. (2005). A systematic review of treatment for music performance anxiety. Anxiety, Stress and Coping, 18, 3,183-208.

Miller, R. (1996). The structure of singing: system and art in vocal technique. New York: London: Schirmer Books.

Miller, R. (1998). The singing teacher in the age of voice science. In R.T. Sataloff (Editor). Vocal health and pedagogy. Singular: San Diego, CA. p. 297-300.

Nair, G. (1999). Voice tradition and technology: a stateof-the-art studio. San Diego: Singular Publishing Group.

Nubé, J. (1991). Beta-blockers: Effects on performing musicians. Medical Problems of Performing Artists, 6, 61-68.

Oates, J., Bain, B., Davis, P., Chapman, J. \& Kenny, D.T. (in press). Development of an auditory-perceptual rating instrument for the operatic singing voice. Journal of Voice. WWw

Parncutt, R. \& McPherson, G.(eds) (2002), The science and psychology of music performance: Creative strategies for teaching and learning. Oxford:Oxford University Press.

Sataloff, R., Rosen, D. C., \& Levy, S. (2000). Performance anxiety: What singing teachers should know. Journal of Singing, 56, 33-40.

Stallibrass, C.; Sissons, P.; \& Chalmers, C. (2002). Randomized controlled trial of the Alexander 
Technique for idiopathic Parkinson's disease. Clinical Rehabilitation, 16, 7, 695-708. ||ww|

Suinn, R. (1997). Mental practice in sport psychology: Where have we been, Where do we go? Clinical Psychology: Science and Practice, 1997, 4, 189-207. Sundberg, J. (1988). The science of the singing voice. DesKalb, Illinois: Northern Illinois University Press. Valentine, E., Fitzgerald, D., Gorton, T., Hudson, J.,
\& Symonds, E. (1995). The effect of lessons in the Alexander technique on music performance in high and low stress situations. Psychology of Music, 23, 129-141.

Vennard, W. (1968). Singing: the mechanism and the technic. 5th ed., New York: Fischer.

Received 27.07.2005 